\title{
Influence of treated waste phosphogypsum materials on the properties of ordinary portland cement
}

\author{
M. S. Al-Hwaiti ${ }^{1 \%}$ \\ ${ }^{1}$ King Saud University, College of Engineering-Muzahimiyah Branch, KSA.
}

\begin{abstract}
In this study, treatment of phosphogypsum (PG) with lime-water (LWT), sulphuric acid (SAT), a mixture of H2SO4 and HNO3 (AWT), PG-water (ST), and PG-limestone (LT) was attempted to purify PG and improve its quality so that it can be used for manufacture of ordinary Portland Cement (OPC). The treatment of $\mathrm{PG}$ removes $\mathrm{P}_{2} \mathrm{O}_{5}, \mathrm{SO}_{3}$, and $\mathrm{MgO}$ impurities into water-leachable phase. Chemical analysis of the treated PG and mechanical properties of OPC mortar after various treatment of PG established improvement of the quality of PG. The purified PG contain less impurities when compared with untreated PG. It was observed that the leachable of $\mathrm{P}_{2} \mathrm{O}_{5}, \mathrm{SO}_{3}$, and $\mathrm{MgO}$ in these samples ranged from $86 \%$ to $90 \%, 69 \%$ to $94 \%, 96 \%$ to $99 \%$, respectively, can be achieved using these treatment processes. The major phases Alite $\left(\mathrm{C}_{3} \mathrm{~S}\right)$, Belite $\left(\mathrm{C}_{2} \mathrm{~S}\right)$, Aluminatetricalcic $\left(\mathrm{C}_{3} \mathrm{~A}\right)$, and Tetra-calcium aluminoferrite $\left(\mathrm{C}_{4} \mathrm{AF}\right)$, and control ratios Lime Saturation factor (LSF), Aluminum/Iron ratio (AR), and Silica ratio (SR) were measured. These experimental results showed that the $\mathrm{C}_{3} \mathrm{~S}, \mathrm{C}_{3} \mathrm{~A}$ and $\mathrm{C}_{4} \mathrm{AF}, \mathrm{C}_{2} \mathrm{~S}$, LSF, AR, and SR contents fulfilled the requirement of the Jordan Standards and European Standards; hence treated PG can be replaced by natural gypsum. The X-ray diffraction analysis of OPC samples showed that $\mathrm{C}_{3} \mathrm{~S}$ and $\mathrm{C}_{2} \mathrm{~S}$ are major mineral phases, $\mathrm{C}_{3} \mathrm{~A}$ and $\mathrm{C}_{4} \mathrm{AF}$ represent as minor constituents while the $\mathrm{CaO}$ and $\mathrm{MgO}$ represent as trace phases. The effect of treated $\mathrm{PG}$ on the mechanical properties of OPC mortar was investigated. The OPC produced with purified phosphogypsum were found to have strength properties similar to those produced from mineral gypsum thus fulfilling Jordan Standards and European Standards. The present study indicates that the use of PG in OPC manufacture can solve the waste disposal problem thus cleaning our environment at one hand, on the other hand it can save natural raw materials i.e gypsum.
\end{abstract}

Keywords: Phosphogypsum; Waste management; Treatment methods; Portland cement; Quality assessment; Compressive strengths

\section{Introduction}

Ordinary Portland cement (OPC) is one of the most widely used material in the constructions sector. Therefore it is important to determine a complete mineralogy of clinker cement to correctly understand, interpret and predict the outcome of any plant production process (Deborah et al., 2009). Every year a huge amount of OPC is produced and used for the construction of building, roads and highways and other local purposes in Jordan.

PG is a by-product of the chemical reaction called the wet process whereby sulphuric acid is reacted with phosphate rock to produce phosphoric acid, needed for fertilizer production. Approximately five tons of PG is produced for every ton of phosphoric acid manufactured (Al-Hwaiti et al., 2010). Through the wet process, some impurities naturally present in the phosphate rock become concentrated in $\mathrm{PG}$, including fluoride, sulfate, phosphates, organic matter, heavy metals, radionuclides, and residual acidity (Neville, 1996). Approximately $58 \%$ of the worldwide PG by-product is stockpiled, $14 \%$ is reprocessed and $28 \%$ is dumped into water bodies (FIPR, 1998). Therefore, attempts were made to use PG in concrete (Smadi et al., 1999; Al-Hwaiti et al., 2013).

A large volume of natural gypsum is used by the cement industry as a set retarder for OPC. It is added to the clinker at the cement grinding stage, usually at a concentration of $5-6 \%$, depending on its purity (Falah, 2011). The use of PG to replace natural gypsum in OPC is minimal, and the main reason for the low demand is its high moisture content and impurities, which interfere with the consistency of the cement (Van der Merwe and Strydom, 2004). The phosphorus, sulfate, fluoride, and organic impurities 
contained in PG interfere in an unpredictable way to delay the setting time, and decrease the mechanical strength development of cement (Singh et al., 2002). It is, thus, clear that PG may not always be suitable for direct use in OPC. Some way has to be found to counteract the harmful influence of impurities, before it can be considered by the cement industry. To solve this problem it is required to produce PG containing few or no impurities. Some of the other methods that have been proposed or adopted for minimizing the effects of impurities in PG are described as follows: washed the PG with water using a $100-\mu \mathrm{m}$ sieve, then heated the PG and added calcium hydroxide to the calcined product in order to improve the setting time and compressive strength of the material produced (Al-Jabbari et al., 1988); investigated the effect of washed PG with water and milk of lime $\mathrm{Ca}(\mathrm{OH})_{2}$, with and without preceding thermal treatment (Erdogan et al., 1994). He reported that the untreated $\mathrm{PG}$ retarded the setting times of OPC and also reduced its strength, but it can be used to control the hydration of cement if washed with milk of lime; another method involves treatment of PG with aqueous citric acid solution which converts phosphates, fluorides and organic matter into insoluble compounds (Singh, 2002). Treatment of PG with a combined thermal and sulpheric acid treatment method has purified phosphorus impurities before it can replace natural gypsum as a set retarder in OPC. These contaminants tend to delay the setting time in unpredictable way, and impair the development of mechanical strength (Van der Merwe and Strydom, 2004). Recently, Weiguo et al. (2012) showed that OPC using PG as retarder has delayed the setting time and difficulty being fed into the cement mill. The soluble phosphates in PG behave as super-retarder and bring about retarding in the setting process of cement made with $\mathrm{PG}$.

PG obtained from the Indo-Jordan Chemical plants in Eshidiya Mines contains greater proportions of impurities, such as phosphate, sulfate, organic matter, fluoride, and acidity. These parameters may seriously affect strength of OPC if used in high volume. There is, therefore, a strong need to investigate preliminary properties of low volume use of (untreated and treated) PG in OPC industry.

Now a days, Jordan PG has not yet been utilized in OPC (Al-Hwaiti et al., 2013). The aim of this study is to: (1) treat PG waste with lime-water (LWT), sulphuric acid (SAT), $\mathrm{H}_{2} \mathrm{SO}_{4}$ and $\mathrm{HNO}_{3}$ mixture (AWT), PG-water (ST), and PG-limestone (LT), in order to reduce chemical oxides such as $\mathrm{MgO}, \mathrm{SO}_{3}$, and $\mathrm{P}_{2} \mathrm{O}_{5}$ content in the studied samples; (2) to investigate the various chemical compounds $\mathrm{C}_{3} \mathrm{~S}, \mathrm{C}_{3} \mathrm{~A}$ and $\mathrm{C}_{4} \mathrm{AF}, \mathrm{C}_{2} \mathrm{~S}, \mathrm{LSF}, \mathrm{AR}$, and $\mathrm{SR}$ in order to assess the hardening of cement and setting time, and the quality of $\mathrm{OPC}$; (3) to evaluate the physical and mechanical properties, in order to improve the hardening of cement and compressive strengths.

\section{Materials and methods}

\section{Materials}

The raw materials were collected from Rashidiya area at Tafila, south Jordan. The raw materials needed to produce cement are generally extracted from limestone rock, clay, and natural gypsum. They are then crushed and transported to the

Table I. The chemical compositions (\%) of the raw materials required for the production of clinker

\begin{tabular}{rcccc}
\hline & Limestone & Clay & Pozzolana & Natural gypsum \\
\hline $\mathrm{CaO}$ & 52.95 & 23.7 & 11.36 & 30.01 \\
$\mathrm{SiO}_{2}$ & 3.32 & 47.19 & 40.97 & 2.02 \\
$\mathrm{Al}_{2} \mathrm{O}_{3}$ & 1.16 & 7.67 & 13.95 & 0.32 \\
$\mathrm{Fe}_{2} \mathrm{O}_{3}$ & 0.67 & 4.14 & 15.11 & - \\
$\mathrm{MgO}$ & 0.50 & 1.69 & 7.55 & 0.06 \\
$\mathrm{MnO}$ & 0.02 & 0.02 & - & - \\
$\mathrm{TiO}_{2}$ & 1.20 & 1.70 & - & - \\
$\mathrm{Na}_{2} \mathrm{O}$ & 0.02 & 0.33 & 0.36 & - \\
$\mathrm{K}_{2} \mathrm{O}$ & 0.18 & 0.76 & 0.04 & - \\
$\mathrm{SO}$ & 0.10 & 0.09 & 45.56 \\
$\mathrm{P}_{2} \mathrm{O}$ & 0.04 & 0.12 & - & 0.01 \\
$\mathrm{~F}$ & 0.03 & 0.00 & - & 0.01 \\
$\mathrm{LOI}$ & 0.00 & 13.62 & 12.70 & 20.26 \\
\hline $\mathrm{Sum}$ & 41.35 & 101.04 & 102.13 & 98.25 \\
\hline
\end{tabular}


Rashidiya cement plant where they are stored and homogenized. The chemical compositions of raw materials: limestone, clay, pozzolana and natural gypsum are listed in Table I. The mixing percentage contents of the raw materials required for the production of clinker is $70 \%, 25 \%, 5 \%$ and $5 \%$, respectively. The moisture contents of the raw mixture supplied to the mills ranged from $4.1 \%$ to $7.6 \%$. Fifteen PG samples were collected from Indo-Jordan Chemicals Company (Fig. 1), weighted $10 \mathrm{Kg}$ each. For every 5 samples, one composite samples were selected, weighted 1 $\mathrm{kg}$ each, ground, dried overnight at $45^{\circ} \mathrm{C}$, and then stored for several treatment methods.
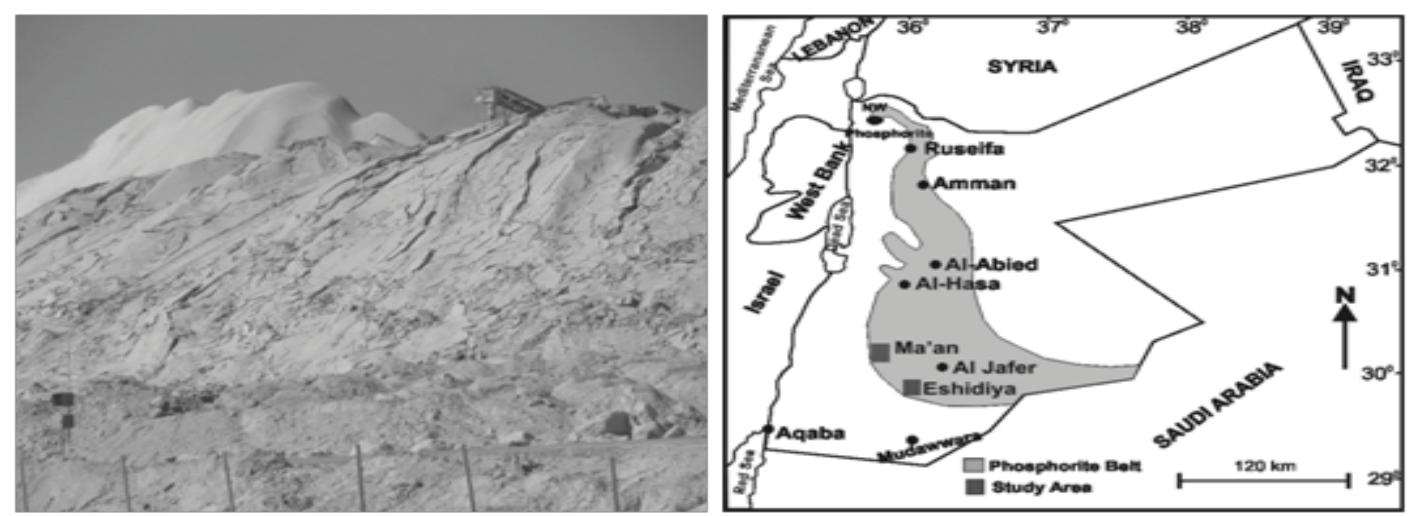

Fig. 1. Samples site and location map of the study area.

Table II. The mix proportions of varying percentage of reagent and PG

\begin{tabular}{|c|c|c|c|c|c|c|c|}
\hline Code & PG & \multicolumn{2}{|c|}{ Reagent } & Reaction Time & $\mathrm{T}$ & Filtered & Dried \\
\hline & $\mathrm{g}$ & & & hour & ${ }^{\circ} \mathrm{C}$ & & ${ }^{\circ} \mathrm{C}$ \\
\hline PG-1 & 200 & - & & - & & - & 85 \\
\hline PG-2 & 200 & - & & - & & - & 85 \\
\hline PG-4 & 200 & - & & - & & - & 65 \\
\hline \multirow[t]{2}{*}{ PG-5 } & 200 & - & & - & & - & 65 \\
\hline & & & & & & \multicolumn{2}{|c|}{ Lime-Water Treatment } \\
\hline LWT2 & 200 & Lime water + Sea water $(v / v)(125 \mathrm{~m}$ & : $675 \mathrm{ml})$ & 24 & 25 & A Büchner funnel & 65 \\
\hline LWT3 & 200 & Lime water + Sea water $(v / v)(150 \mathrm{~m}$ & : $650 \mathrm{ml})$ & 24 & 25 & A Büchner funnel & 65 \\
\hline LWT4 & 200 & Lime water + Tap water $(\mathrm{v} / \mathrm{v})(100 \mathrm{~m}$ & : $700 \mathrm{ml})$ & 24 & 25 & A Büchner funnel & 65 \\
\hline LWT5 & 200 & Lime water + Tap water $(\mathrm{v} / \mathrm{v})(100 \mathrm{~m}$ & : $700 \mathrm{ml})$ & 24 & 25 & A Büchner funnel & 65 \\
\hline LWT6 & 200 & Lime water + Distilled water $(\mathrm{v} / \mathrm{v})(100 \mathrm{~m}$ & : $700 \mathrm{ml})$ & 24 & 25 & A Büchner funnel & 65 \\
\hline \multirow[t]{2}{*}{ LWT7 } & 200 & Lime water + Distilled water $(\mathrm{v} / \mathrm{v})(1250 \mathrm{~m}$ & : $675 \mathrm{ml})$ & 24 & 25 & A Büchner funnel & 65 \\
\hline & & & & & \multicolumn{3}{|c|}{ Sulphuric acid + Water Treatment } \\
\hline SAT2 & 200 & $5 \%$ Sulphuric acid + Tap water $(\mathrm{v} / \mathrm{v})(12$ & l: $88 \mathrm{ml})$ & 24 & 25 & A Büchner funnel & 65 \\
\hline SAT3 & 200 & $5 \%$ Sulphuric acid + Distiled water (v/v) (12 & l: $88 \mathrm{ml})$ & 24 & 25 & A Büchner funnel & 65 \\
\hline SAT4 & 200 & $5 \%$ Sulphuric acid + Limewater (v/v) (12 & l: $88 \mathrm{ml})$ & 24 & 25 & A Büchner funnel & 65 \\
\hline & & & & & \multicolumn{3}{|c|}{$\left(\mathrm{H}_{2} \mathrm{SO}_{4}+4 \mathrm{ml} 2 \% \mathrm{HNO}_{3}\right)+$ Water Treatment } \\
\hline AWT1 & 200 & $300 \mathrm{ml} 5 \% \mathrm{H}_{2} \mathrm{SO}_{4}+4 \mathrm{ml} 2 \% \mathrm{HNO}_{3}+$ Distilled water $(\mathrm{v} / \mathrm{v})(250 \mathrm{~m}$ & : $750 \mathrm{ml})$ & 24 & 25 & A Büchner funnel & 65 \\
\hline AWT2 & 200 & $300 \mathrm{ml} 5 \% \mathrm{H}_{2} \mathrm{SO}_{4}+4 \mathrm{ml} 2 \% \mathrm{HNO}_{3}+$ Distilled water $(\mathrm{v} / \mathrm{v})(300 \mathrm{~m}$ & : $700 \mathrm{ml})$ & 24 & 25 & A Büchner funnel & 65 \\
\hline \multirow{4}{*}{$\begin{array}{l}\text { ST1 } \\
\text { ST2 }\end{array}$} & & & & & & \multicolumn{2}{|c|}{ PG + Water Treatment } \\
\hline & 200 & Tap water & $(100 \mathrm{ml})$ & 24 & 25 & A Büchner funnel & 65 \\
\hline & 200 & Distilled water & $(200 \mathrm{ml})$ & 24 & 25 & A Büchner funnel & 65 \\
\hline & & & & & & \multicolumn{2}{|c|}{ PG + Limestone Treatment } \\
\hline LT1 & 200 & Limestone & $(5 \mathrm{~g})$ & - & - & - & - \\
\hline LT2 & 200 & Limestone & $(10 \mathrm{~g})$ & - & - & - & - \\
\hline LT3 & 200 & Limestone & $(25 \mathrm{~g})$ & - & - & - & - \\
\hline LT4 & 200 & Limestone & $(50 \mathrm{~g})$ & - & - & - & - \\
\hline LT5 & 200 & Limestone & $(75 \mathrm{~g})$ & - & - & - & - \\
\hline
\end{tabular}




\section{Batch Purification of phosphogypsum}

Three composite PG samples were subjected for each treatment: lime-Water treatment (LWT), sulphuric acid treatment (SAT), $\mathrm{H}_{2} \mathrm{SO}_{4}$ and $\mathrm{HNO}_{3}$ mixing treatment (AWT), PG-Water treatment (ST), PG-Limestone treatment (LT) reagent process. The mix proportions were composed of varying percentage of reagent and $P G$ are summarized in Table II. The PG samples where thoroughly shaken with aqueous solution in a mechanical shaker for 24 hours at ambient temperature, filtered through a Buckner funnel and then dried overnight at $65^{\circ} \mathrm{C}$. Batch purification experiments were conducted in polyethylene bottles.

\section{Ordinary portland cement $(O P C)$ tests}

Sixty six purified PG samples produced from batch experiments were mixed with clinker from Rashidiya cement plant. OPC was produced by mixing of $95 \%$ of clinker and $5 \%$ of purified PG. The grindability or crushing is determined by comparing the increase in fineness in material and the energy spent for such increase. Approximately $95 \%$ of OPC particles are smaller than $45 \mu$ with average of particle size about $15 \mu$. The initial setting time ranged from 110 to $120 \mathrm{~min}$, whereas the final setting ranged from 580 to $600 \mathrm{~min}$. Good quality cement requires adequate fineness corresponding to a specific surface ranging from 3200 and 3500 Blaine $\left(\mathrm{cm}^{2} / \mathrm{g}\right)$. The monitoring of quality control of cement is pre-requisite to start the study of the PG based cement. The physical properties of the OPC were determined by measuring specific surface area, specific gravity, and bulk density of OPC was performed according to the ASTM C597, ASTM C39 and ASTM C188. Specific surface area of OPC ranges between $300 \mathrm{~m} 2 / \mathrm{kg}$ and $320 \mathrm{~m} 2 / \mathrm{kg}$. Specific gravity of OPC is found to be in the range of 3.10 to 3.25 . Bulk density of OPC ranges from $830 \mathrm{~kg} / \mathrm{m}$ to $1650 \mathrm{~kg} / \mathrm{m}$.

\section{Chemical analysis}

\section{$X$-ray fluorescence $(X R F)$}

Eight $\mathrm{PG}$ samples were analyzed for major and minor oxides of $\mathrm{CaO}, \mathrm{SiO}_{2}, \mathrm{Al}_{2} \mathrm{O}_{3}, \mathrm{Fe}_{2} \mathrm{O}_{3}, \mathrm{MgO}, \mathrm{Na}_{2} \mathrm{O}, \mathrm{K}_{2} \mathrm{O}$, and $\mathrm{SO}_{3}$ by using X-ray fluorescence (SIM XRF ARL 8405) at the Research Department, Jordan Phosphate Mines Company (JPMC). Sixty six OPC samples for major oxides $\mathrm{CaO}, \mathrm{SiO}_{2}, \mathrm{Al}_{2} \mathrm{O}_{3}, \mathrm{Fe}_{2} \mathrm{O}_{3}, \mathrm{MgO}, \mathrm{Na}_{2} \mathrm{O}, \mathrm{K}_{2} \mathrm{O}$, and $\mathrm{SO}_{3}$ were analyzed by using X-ray analyzer (ARL WIN XRF V3.1-2) at Rashidiya cement plant. $\mathrm{C}_{2} \mathrm{~S}, \mathrm{C}_{3} \mathrm{~A}, \mathrm{C}_{4} \mathrm{AF}$, $\mathrm{C}_{3} \mathrm{~S}$, and LOI for OPC were measured by using ARL win XRF V 3.1-2. The $\mathrm{SO}_{3}$ content of each gypsum sample was first determined by a wet chemical method, and each of the gypsum samples was then mixed with the clinker to achieve a final $\mathrm{SO}_{3}$ content of $3.1 \%$ in the cement.

\section{Preparation of specimens and testing}

Sixty six OPC mixes were made for each type of PG purified. Each mix was prepared to produce mortar specimens that are needed to assess the compressive strength in addition to other tests that might be needed for SEM and XRD tests. All OPC specimens were cast in $16 \times 4 \times 4 \mathrm{~cm}$ molds for testing compressive strength of cement mortar. Measurements were made for 2 and 28 days. The compressive strength tests were carried out according to EN 196-1.

\section{Quality assessment of $O P C$}

The principal constituents of OPC are tricalcium silicate $\left(3 \mathrm{CaO} . \mathrm{SiO}_{2}\right)$, dicalcium silicate $\left(2 \mathrm{CaO} . \mathrm{SiO}_{2}\right)$, tricalcium aluminate $\left(3 \mathrm{CaO} \cdot \mathrm{Al}_{2} \mathrm{O}_{3}\right)$ and tetracalcium aluminoferrite $\left(4 \mathrm{CaO} \cdot \mathrm{Al}_{2} \mathrm{O}_{3} \cdot \mathrm{Fe}_{2} \mathrm{O}_{3}\right)$ and they are designated as $\mathrm{C}_{3} \mathrm{~S}, \mathrm{C}_{2} \mathrm{~S}$, $\mathrm{C}_{3} \mathrm{~A}$, and $\mathrm{C}_{4} \mathrm{AF}$ respectively (Lobthenbach et al. 2006). $\mathrm{C}_{3} \mathrm{~S}$ and $\mathrm{C}_{2} \mathrm{~S}$ are responsible for strength development. $\mathrm{C}_{3} \mathrm{~A}$ and $\mathrm{C}_{4} \mathrm{AF}$ control setting and heat evolution during hydration (Natalya, 2003). The properties of the cement, such as its setting time and strength, are adjusted by the addition of gypsum and by grinding to specific degrees of fineness (Wagner and Vassilopoulos, 2000). The compositions of the constituents are used to determine the quality of the OPC. The quality of the cement products were calculated from the oxide concentrations of the cement using Bogue formulae (Ali et al., 2008). The lime saturation factor, the silica and aluminum ratios were calculated from the percentage oxide compositions (Charles et al., 2010). The formulae for the calculation are as follows:

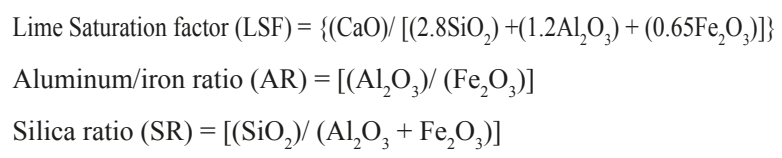

\section{Results and discussion}

\section{Influence of chemical composition in OPC products}

The eight major oxides $\mathrm{P}_{2} \mathrm{O}_{5}, \mathrm{SiO}_{2}, \mathrm{CaO}, \mathrm{Al}_{2} \mathrm{O}_{3}, \mathrm{Fe}_{2} \mathrm{O}_{3}, \mathrm{MgO}$, $\mathrm{SO}_{3}$, and L.O.I in the PG from Eshidiya are summarized in Table III. Examination of the data in Table III showed that the major oxides concentration in the samples less varied considerably, most notably, $\mathrm{SO}_{3}$ concentrations in PG-1, PG-2, PG-3, PG-4, PG-5, PG-6, PG-7, PG-8 were $41.42 \%$, $42.50 \%, 43.20 \%, 42.40 \%, 41.76 \%, 41.80 \%, 41.80 \%$ and $42.70 \%$, respectively. Chemical analysis of major oxides of treated $\mathrm{PG}$ is shown in Table $\mathrm{V}$. The mean perecntage of $\mathrm{CaO}$ content in the LWT, SAT, AWT, ST, and LT are $63.89 \%$, $63.77 \%, 63.70 \%, 64.00 \%$, and $64.38 \%$, respectively. Amount 
Table III. Chemical composition (\%) of PG from Indo-Jordan chemical at Eshidiya Mines

\begin{tabular}{rllllllll}
\hline & $\mathrm{P}_{2} \mathrm{O}_{5}$ & $\mathrm{SiO}_{2}$ & L.O.I & $\mathrm{CaO}$ & $\mathrm{Al}_{2} \mathrm{O}_{3}$ & $\mathrm{Fe}_{2} \mathrm{O}_{3}$ & $\mathrm{MgO}$ & $\mathrm{SO}_{3}$ \\
\hline PG-1 & 4.89 & 11.29 & 10.10 & 33.30 & 0.73 & 0.34 & 0.27 & 41.42 \\
PG-2 & 4.64 & 11.27 & 10.12 & 33.20 & 0.48 & 0.20 & 0.10 & 42.50 \\
PG-3 & 5.02 & 11.55 & 10.40 & 32.20 & 0.45 & 0.26 & 0.09 & 43.20 \\
PG-4 & 4.57 & 15.15 & 10.70 & 30.65 & 0.45 & 0.22 & 0.08 & 42.40 \\
PG-5 & 4.37 & 11.62 & 10.88 & 31.50 & 0.42 & 0.18 & 0.07 & 41.76 \\
PG-6 & 4.52 & 10.66 & 10.10 & 31.90 & 0.50 & 0.20 & 0.09 & 41.86 \\
PG-7 & 4.95 & 11.63 & 10.90 & 32.12 & 0.69 & 0.29 & 0.13 & 41.80 \\
PG-8 & 4.80 & 10.41 & 10.65 & 32.27 & 0.44 & 0.17 & 0.08 & 42.70 \\
Average & 4.72 & 12.45 & 10.48 & 32.14 & 0.52 & 0.23 & 0.11 & 42.20 \\
STD & 0.23 & 2.44 & 0.35 & 0.86 & 0.12 & 0.06 & 0.07 & 2.75 \\
\hline
\end{tabular}

Table IV. Chemical analysis of major oxides (\%) of treated PG

\begin{tabular}{|c|c|c|c|c|c|c|c|c|c|}
\hline & \multicolumn{4}{|c|}{$\mathrm{SO}_{3}$} & \multicolumn{2}{|c|}{$\mathrm{MgO}$} & \multicolumn{3}{|c|}{$\mathrm{P}_{2} \mathrm{O}_{5}$} \\
\hline & $\mathrm{T}$ & $\mathrm{Cx}$ & L \% & $\mathrm{T}$ & $\mathrm{Cx}$ & L \% & $\mathrm{T}$ & $\mathrm{Cx}$ & L \% \\
\hline LWT-1 & 42.2 & 40.91 & 96.94 & 0.11 & 0.108 & 98.18 & 4.72 & 4.18 & 88.56 \\
\hline LWT-2 & 42.2 & 34.82 & 82.51 & 0.11 & 0.109 & 99.09 & 4.72 & 4.13 & 87.50 \\
\hline LWT-3 & 42.2 & 35.68 & 84.55 & 0.11 & 0.108 & 98.18 & 4.72 & 4.15 & 87.92 \\
\hline LWT-4 & 42.2 & 34.66 & 82.13 & 0.11 & 0.109 & 99.09 & 4.72 & 4.17 & 88.35 \\
\hline LWT-5 & 42.2 & 37.85 & 89.69 & 0.11 & 0.109 & 99.09 & 4.72 & 4.15 & 87.92 \\
\hline LWT-6 & 42.2 & 38.99 & 92.39 & 0.11 & 0.109 & 99.09 & 4.72 & 4.16 & 88.14 \\
\hline LWT-7 & 42.2 & 35.86 & 84.98 & 0.11 & 0.109 & 99.09 & 4.72 & 4.15 & 87.92 \\
\hline Average & 42.20 & 36.97 & 87.60 & 0.11 & 0.11 & 98.83 & 4.72 & 4.16 & 88.04 \\
\hline SAT-1 & 42.2 & 41.13 & 97.46 & 0.11 & 0.107 & 97.27 & 4.72 & 4.22 & 89.41 \\
\hline SAT-2 & 42.2 & 37.96 & 89.95 & 0.11 & 0.109 & 99.09 & 4.72 & 4.23 & 89.62 \\
\hline SAT-3 & 42.2 & 41.3 & 97.87 & 0.11 & 0.108 & 98.18 & 4.72 & 4.20 & 88.98 \\
\hline SAT-4 & 42.2 & 37.29 & 88.36 & 0.11 & 0.107 & 97.27 & 4.72 & 4.18 & 88.56 \\
\hline Average & 42.20 & 39.42 & 93.41 & 0.11 & 0.11 & 97.95 & 4.72 & 4.21 & 89.14 \\
\hline AWT-1 & 42.2 & 41.05 & 97.27 & 0.11 & 0.108 & 98.18 & 4.72 & 4.13 & 87.50 \\
\hline AWT-2 & 42.2 & 38.6 & 91.47 & 0.11 & 0.109 & 99.09 & 4.72 & 4.15 & 87.92 \\
\hline AWT -3 & 42.2 & 38.23 & 90.59 & 0.11 & 0.107 & 97.27 & 4.72 & 4.14 & 87.71 \\
\hline Average & 42.20 & 39.29 & 93.11 & 0.11 & 0.11 & 98.18 & 4.72 & 4.14 & 87.71 \\
\hline ST-1 & 42.2 & 39.38 & 93.32 & 0.11 & 0.108 & 98.18 & 4.72 & 4.22 & 89.41 \\
\hline ST-2 & 42.2 & 39.97 & 94.72 & 0.11 & 0.108 & 98.18 & 4.72 & 4.25 & 90.04 \\
\hline ST-3 & 42.2 & 39.27 & 93.06 & 0.11 & 0.11 & 99.09 & 4.72 & 4.26 & 90.25 \\
\hline Average & 42.20 & 39.54 & 93.70 & 0.11 & 0.11 & 98.48 & 4.72 & 4.24 & 89.90 \\
\hline LT-1 & 42.2 & 30.43 & 72.11 & 0.11 & 0.105 & 95.45 & 4.72 & 4.10 & 86.86 \\
\hline LT-2 & 42.2 & 29.53 & 69.98 & 0.11 & 0.106 & 96.36 & 4.72 & 4.11 & 87.08 \\
\hline LT-3 & 42.2 & 30.87 & 73.15 & 0.11 & 0.107 & 97.27 & 4.72 & 4.08 & 86.44 \\
\hline LT-4 & 42.2 & 30.34 & 71.90 & 0.11 & 0.106 & 96.36 & 4.72 & 4.04 & 85.59 \\
\hline LT-5 & 42.2 & 24.96 & 59.15 & 0.11 & 0.105 & 95.45 & 4.72 & 4.08 & 86.44 \\
\hline Average & 42.20 & 29.23 & 69.26 & 0.11 & 0.11 & 96.18 & 4.72 & 4.08 & 86.48 \\
\hline
\end{tabular}

$\mathrm{T}=$ Total, $\mathrm{CX}=$ Leaching, $\mathrm{L}=$ Leaching $(\% \mathrm{~L})=(\mathrm{Cx} * \mathrm{CaO} / \mathrm{TCaO}) * 100 \%$

of $\mathrm{CaO}$ as specified in OPC by the British standards, Jordan Standards, and European Standards should be within the range $63 \%$ to $67 \%, 61 \%$ to $65 \%, 61 \%$ to $67 \%$, respectively (Ali et al., 2008). According to Neville (1996) the proper lime content is limited due to the lower early strength produced when lime content of OPC is too low, and unsoundness when it is too high. High $\mathrm{CaO}$ content is associated with early strength whereas; slightly lower content of lime favors ultimate strength which develops gradually over a long period of time (Pandey and Shukla, 1980). In order to increase the strength it is necessary to increase the lime content, or grind finer. But higher temperatures are required to burn the high lime mixtures (Neville, 1996). The mean concentrations of $\mathrm{SiO}_{2}$ in the LWT, SAT, AWT, ST, and LT are $21.39 \%, 21.42 \%, 21.00 \%, 21.30 \%$, and $21.60 \%$, respectively (Table V). British Standards, Jordan Standards, and European standards specify amounts of $\mathrm{SiO}_{2}$ in Portland cement within the range of $21 \%$ to $22 \%, 18 \%$ to $21 \%$, and $19 \%$ to $21 \%$, respectively. Hence treated PG could be replaced by natural gypsum. 
The mean concentrations of $\mathrm{Al}_{2} \mathrm{O}_{3}$ in the LWT, SAT, AWT, ST, and LT are $5.07 \%, 5.08 \%, 5.10 \%, 5.07 \%$, and $4.72 \%$, respectively. The Jordan standards and European standards specify amounts of $\mathrm{Al}_{2} \mathrm{O}_{3}$ in $\mathrm{OPC}$ within the range of $4 \%$ to $6 \%$ and $2 \%$ to $6 \%$ (Tamas, 2010). The mean concentrations of $\mathrm{Fe}_{2} \mathrm{O}_{3}$ in the LWT, SAT, AWT, ST, and LT are $3.28 \%$, $3.27 \%, 3.30 \%, 3.29 \%$, and $3.32 \%$, respectively. However, the amount of $\mathrm{Al}_{2} \mathrm{O}_{3}$ and $\mathrm{Fe}_{2} \mathrm{O}_{3}$ in OPC are within the specified limit, indicating that the $\mathrm{CaO}$ content is specified limit, and the silica becomes specified limit, which may be accompanied by a specified limit in alumina and ferric oxide, the temperature of burning will not be raised and the special influence of the high lime will not be lost, which appear to be of high value for their cementing qualities. This results is confirmed by

(Neville, 1996), if the $\mathrm{CaO}$ content is fixed, and the silica becomes too high, which may be accompanied by a decrease in alumina and ferric oxide, the temperature of burning will be raised and the special influence of the high lime will be lost. If the lime content is too low, which means an increase in the alumina and ferric oxide, the cement may become quick-setting and contain a larger amount of alumina compounds, which appear to be of little value for their cementing qualities. Rapid setting is undesirable, and is not permitted by the standard specifications, because the cement sets up so rapidly that it cannot properly be worked in the forms before stiffening occurs.

The mean concentrations of $\mathrm{MgO}$ in the LWT, SAT, AWT, ST, and LT are $2.52 \%, 2.98 \%, 2.20 \%, 2.48 \%$, and $2.19 \%$, respectively. According to Jordan standard and EU specification the $\mathrm{MgO}$ content in $\mathrm{OPC}$ would be $<5 \%$. $\mathrm{MgO}$ contents have a detrimental effect on the soundness of the coarse, especially at late ages. Austin (1985) showed that high magnesium oxide reacts with water to form $\mathrm{Mg}(\mathrm{OH})_{2}$, and this is the slowest reaction among all other hardening reactions. Since $\mathrm{Mg}(\mathrm{OH})_{2}$ occupies a larger volume than the $\mathrm{MgO}$ and is formed on the same spot where the $\mathrm{MgO}$ particle is located, it can split apart the binding of the hardened cement paste, resulting in expansion cracks commonly known as magnesia expansion. In this study, the average percentage leach of $\mathrm{MgO}$ was found to be $98 \%, 98 \%, 98 \%$, $98 \%$, and $96 \%$ from original $\mathrm{MgO}$ present in LWT, SAT, AWT, ST, and LT, respectively (Table IV), indicating that the leach of $\mathrm{MgO}$ showed that low magnesium oxide reacts with water to form $\mathrm{Mg}(\mathrm{OH})_{2}$.

The mean concentrations of $\mathrm{SO}_{3}$ in the LWT, SAT, AWT, ST, and LT are $2.98 \%, 3.32 \%, 3.60 \%, 3.13 \%$, and $3.29 \%$, respectively. According to Jordan standard and EU specification the $\mathrm{SO}_{3}$ content in $\mathrm{OPC}$ ranged from $2.70 \%$ to $3.50 \%$, from $1.50 \%$ to $2.50 \%$ respectively, (Faleye et al., 2009), indicating that the allowable $\mathrm{SO}_{3}$ content in the cement will prevent sulfate expansion. In this study, the average percentage leach of $\mathrm{SO}_{3}$ was found to be $88 \%, 93 \%, 93 \%$, $94 \%, 69 \%$ from original $\mathrm{SO}_{3}$ present in LWT, SAT, AWT, ST, and LT, respectively (Table IV), indicating that the leach of $\mathrm{SO}_{3}$ showed that setting time effectively decreased and then improved OPC standard specification.

The mean concentrations of loss on ignition (LOI) in the LWT, SAT, AWT, ST, and LT are $3.01 \%, 3.13 \%, 3.15 \%$, $3.11 \%$, and $3.23 \%$, respectively. LOI of the all samples were found to conform as specified by the Jordan standards and EU Standards. It can be concluded that the allowable LOI indicates non-hydration and non-carbonation, which may be caused by appropriate storage or adulteration of OPC during transport or transfer. The possible reasons of variations are specification of raw mix, uniformity of mixture, and decrease impurities from various stages of processing, and intentional alteration. Variations in chemical constituents affect the OPC properties like, hardening/hydration, setting time, corrosion resistance, color, etc (Pandey and Shukla, 1980). The OPC produced with purified $\mathrm{PG}$ were found to have $\mathrm{CaO}, \mathrm{SiO}_{2}$, $\mathrm{Al}_{2} \mathrm{O}_{3}, \mathrm{Fe}_{2} \mathrm{O}_{3}, \mathrm{MgO}, \mathrm{SO}_{3}$, and LOI chemical compositions similar to those produced from mineral gypsum thus fulfilling Jordan Standards and European Standards.

OPC always contains phosphorus in the range 0.2 to 0.3 weight percent (wt. \%) $\mathrm{P}_{2} \mathrm{O}_{5}$ (Kwon et al., 2005). The effect of phosphorus was studied in order to validate the use of phosphorus-rich limestone quarries, such as the phosphatic rocks, however, in this study clinkers phosphorus concentration was above 1 wt. \% P. The major effect of phosphorus addition is to decrease the $\mathrm{C}_{3} \mathrm{~S} / \mathrm{C}_{2} \mathrm{~S}$ ratio, with a strong deterioration of the mechanical properties of the hydrated $\mathrm{OPC}$, since $\mathrm{C}_{3} \mathrm{~S}$ is the main hydraulic phase in clinker. For each additional of $\mathrm{P}_{2} \mathrm{O}_{5}$ above 1 wt. \%, the $\mathrm{C}_{3} \mathrm{~S}$ concentration decreases with 9.9 wt. \% whereas the $\mathrm{C}_{2} \mathrm{~S}$ concentration increases with 10.9 wt. \%. Above 2.25 wt. \% $\mathrm{P} 2 \mathrm{O}$, the clinker is no more acceptable for cement production. In this study, the mean concentrations of $\mathrm{P}_{2} \mathrm{O}_{5}$ in the LWT, SAT, AWT, ST, and LT are $0.56 \%, 0.51 \%$, $0.58 \%, 0.48 \%$, and $0.64 \%$, respectively. All the OPC samples were found to be competent with regard to maximum $\mathrm{P}_{2} \mathrm{O}_{5}$ limit range should be $0-1 \%$, and preferable range should be $0.3-0.5 \%$ as specified by the Jordan Standards and EU Standards. It can be concluded that the allowable $\mathrm{P}_{2} \mathrm{O}_{5}$ accelerates the clinkerization reaction, reduces the intensity of internal volatile cycle, reduces the early strength, and reduces $\mathrm{C}_{3} \mathrm{~S}$ content (Taylor, 1997).

\section{Quality assessment of OPC by XRD}

Fig. 2. shows that the major constituents of OPC: $\mathrm{Ca}_{3} \mathrm{SiO}_{5}$ $\left(\mathrm{C}_{3} \mathrm{~S}\right), \mathrm{Ca}_{2} \mathrm{SiO}_{4}\left(\mathrm{C}_{2} \mathrm{~S}\right), \mathrm{Ca}_{3} \mathrm{Al}_{2} \mathrm{O}_{6}\left(\mathrm{C}_{3} \mathrm{~A}\right), \mathrm{Ca}_{4} \mathrm{Al}_{2} \mathrm{Fe}_{2} \mathrm{O}_{10}\left(\mathrm{C}_{4} \mathrm{AF}\right)$ (Taylor, 1997). The X-ray diffraction analysis of OPC 
Table V. Chemical compositions of natural gypsum, PG, treated PG and OPC

\begin{tabular}{|c|c|c|c|c|c|c|c|c|c|c|c|c|c|}
\hline Elements & $\mathrm{CaO}$ & $\mathrm{SiO}_{2}$ & $\mathrm{Al}_{2} \mathrm{O}_{3}$ & $\mathrm{Fe}_{2} \mathrm{O}_{3}$ & $\mathrm{MgO}$ & $\mathrm{SO}_{3}$ & $\mathrm{C}_{3} \mathrm{~S}$ & $\mathrm{C}_{4} \mathrm{AF}$ & $\mathrm{C}_{3} \mathrm{~A}$ & $\mathrm{C}_{2} \mathrm{~S}$ & LSF & $\mathrm{AR}$ & SR \\
\hline Natural gypsum & 60.90 & 20.30 & 5.40 & 3.80 & 4.40 & 3.10 & 42.75 & 25.95 & 7.88 & 15.00 & 0.93 & 1.42 & 2.21 \\
\hline PG (untreated) & 62.30 & 21.80 & 5.10 & 3.50 & 1.60 & 2.90 & 40.08 & 32.26 & 7.59 & 14.70 & 0.90 & 1.46 & 2.53 \\
\hline OPC (JS-STD) & 65.60 & 21.00 & 5.50 & 3.30 & 1.40 & 2.70 & 57.74 & 26.65 & 8.99 & 10.04 & 0.97 & 1.67 & 2.39 \\
\hline OPC (EU-STD) & 66.20 & 23.30 & 5.13 & 3.53 & 0.83 & 0.27 & 51.82 & 27.71 & 7.62 & 10.74 & 0.90 & 1.45 & 2.69 \\
\hline LWT-1 & 63.62 & 21.19 & 4.99 & 3.28 & 2.20 & 3.07 & 50.67 & 22.53 & 7.67 & 9.98 & 0.94 & 1.52 & 2.56 \\
\hline LWT-2 & 63.99 & 21.62 & 5.12 & 3.29 & 3.29 & 2.87 & 48.58 & 25.33 & 8.00 & 10.01 & 0.93 & 1.56 & 2.57 \\
\hline LWT-3 & 63.68 & 21.21 & 5.08 & 3.3 & 2.72 & 3.00 & 50.32 & 22.85 & 7.88 & 10.04 & 0.94 & 1.54 & 2.53 \\
\hline LWT-4 & 64.01 & 21.55 & 5.07 & 3.26 & 2.25 & 2.95 & 49.35 & 24.55 & 7.92 & 9.92 & 0.93 & 1.56 & 2.59 \\
\hline LWT-5 & 63.99 & 21.47 & 5.03 & 3.27 & 2.19 & 3.09 & 49.73 & 24.04 & 7.80 & 9.95 & 0.94 & 1.54 & 2.59 \\
\hline LWT-6 & 64.18 & 21.46 & 5.09 & 3.24 & 2.23 & 2.92 & 50.70 & 23.27 & 8.01 & 9.86 & 0.94 & 1.57 & 2.58 \\
\hline LWT-7 & 63.75 & 21.26 & 5.13 & 3.31 & 2.73 & 2.97 & 49.96 & 23.26 & 7.99 & 10.07 & 0.94 & 1.55 & 2.52 \\
\hline Average & 63.89 & 21.39 & 5.07 & 3.28 & 2.52 & 2.98 & 49.90 & 23.69 & 7.90 & 9.98 & 0.94 & 1.55 & 2.56 \\
\hline SAT-1 & 63.98 & 21.46 & 5.10 & 3.18 & 2.23 & 3.31 & 48.80 & 24.71 & 8.13 & 9.68 & 0.94 & 1.60 & 2.59 \\
\hline SAT-2 & 63.52 & 21.35 & 5.06 & 3.32 & 2.72 & 3.27 & 47.94 & 25.04 & 7.79 & 10.10 & 0.93 & 1.52 & 2.55 \\
\hline SAT-3 & 63.95 & 21.42 & 5.05 & 3.27 & 2.2 & 3.38 & 48.99 & 24.45 & 7.85 & 9.95 & 0.94 & 1.54 & 2.57 \\
\hline SAT-4 & 63.63 & 21.46 & 5.12 & 3.32 & 4.75 & 3.31 & 47.04 & 26.04 & 7.95 & 10.10 & 0.93 & 1.54 & 2.54 \\
\hline Average & 63.77 & 21.42 & 5.08 & 3.27 & 2.98 & 3.32 & 48.19 & 25.06 & 7.93 & 9.96 & & 1.55 & \\
\hline AWT-1 & 62.5 & 21 & 5.1 & 3.2 & 2.1 & 3.3 & 50.05 & 22.1 & 7.75 & 9.93 & 0.95 & 1.4 & 2.3 \\
\hline AWT-2 & 64.9 & 21 & 5.1 & 3.4 & 2.3 & 3.9 & 50.15 & 22.42 & 7.93 & 10.07 & 0.95 & 1.55 & 2.5 \\
\hline AWT -3 & 63.8 & 21 & 5.1 & 3.3 & 2.2 & 3.6 & 50.25 & 22.59 & 8.11 & 10.12 & 0.95 & 1.7 & 2.7 \\
\hline Average & 63.7 & 21 & 5.1 & 3.3 & 2.2 & 3.6 & 50.15 & 22.37 & 7.93 & 10.04 & 0.95 & 1.55 & 2.5 \\
\hline ST-1 & 63.86 & 21.22 & 5.04 & 3.3 & 2.71 & 3.26 & 50.51 & 22.73 & 7.77 & 10.04 & 0.94 & 1.53 & 2.54 \\
\hline ST-2 & 64.14 & 21.38 & 5.05 & 3.27 & 2.4 & 3.02 & 50.65 & 22.81 & 7.85 & 9.98 & 0.94 & 1.52 & 2.54 \\
\hline ST-3 & 64.2 & 21.42 & 5.12 & 3.31 & 2.32 & 3.1 & 50.90 & 22.92 & 7.97 & 9.98 & 0.94 & 1.58 & 2.57 \\
\hline Average & 64 & 21.3 & 5.07 & 3.29 & 2.48 & 3.13 & 50.69 & 22.82 & 7.86 & 10.00 & 0.94 & 1.54 & 2.55 \\
\hline LT-1 & 63.73 & 21.06 & 4.78 & 3.2 & 2.08 & 3.08 & 53.62 & 19.93 & 7.25 & 9.74 & 0.95 & 1.49 & 2.64 \\
\hline LT-2 & 63.61 & 20.96 & 4.76 & 3.19 & 2.07 & 3.15 & 53.84 & 19.48 & 7.22 & 9.71 & 0.96 & 1.49 & 2.64 \\
\hline LT-3 & 63.81 & 20.49 & 4.62 & 3.16 & 2.03 & 3.71 & 57.62 & 15.28 & 6.90 & 9.62 & 0.98 & 1.46 & 2.63 \\
\hline LT-4 & 64.66 & 20.15 & 4.59 & 3.12 & 2.01 & 3.06 & 65.78 & 8.15 & 6.88 & 9.49 & 1.01 & 1.47 & 2.61 \\
\hline LT-5 & 66.10 & 20.36 & 4.85 & 3.92 & 2.76 & 3.45 & 66.02 & 8.56 & 6.22 & 11.93 & 1.01 & 1.24 & 2.32 \\
\hline Average & 64.38 & 20.60 & 4.72 & 3.32 & 2.19 & 3.29 & 59.37 & 14.28 & 6.89 & 10.10 & 0.98 & 1.43 & 2.56 \\
\hline
\end{tabular}

Table VI. Physical characteristics of OPC tests containing treated PG

\begin{tabular}{rrrrrrr}
\hline Physical property & LWT & SAT & AWT & ST & LT \\
\hline & Blaine surface area $\left(\mathrm{cm}^{2} / \mathrm{g}\right)$ & 3200 & 3500 & 3200 & 3300 & 3200 \\
& Specific gravity & 3.15 & 3.10 & 3.12 & 3.17 & 3.25 \\
& Unit weight $\left(\mathrm{kg} / \mathrm{m}^{3}\right)$ & 2400 & 2480 & 2300 & 2250 & 2500 \\
Initial setting time (min) & - Final setting time (min) & $115-600$ & $112-590$ & $108-596$ & $110-580$ & $120-600$ \\
\hline
\end{tabular}


samples showed that $\mathrm{C}_{3} \mathrm{~S}$ and $\mathrm{C}_{2} \mathrm{~S}$, as a major mineral phase, $\mathrm{C}_{3} \mathrm{~A}$ and $\mathrm{C}_{4} \mathrm{AF}$ are represents as minor constituents while the free lime $\mathrm{CaO}$ and Periclase $\mathrm{MgO}$ present as trace phases. The mean percentage proportions of $\mathrm{C}_{3} \mathrm{~S}, \mathrm{C}_{2} \mathrm{~S}, \mathrm{C}_{3} \mathrm{~A}$ and $\mathrm{C}_{4} \mathrm{AF}$

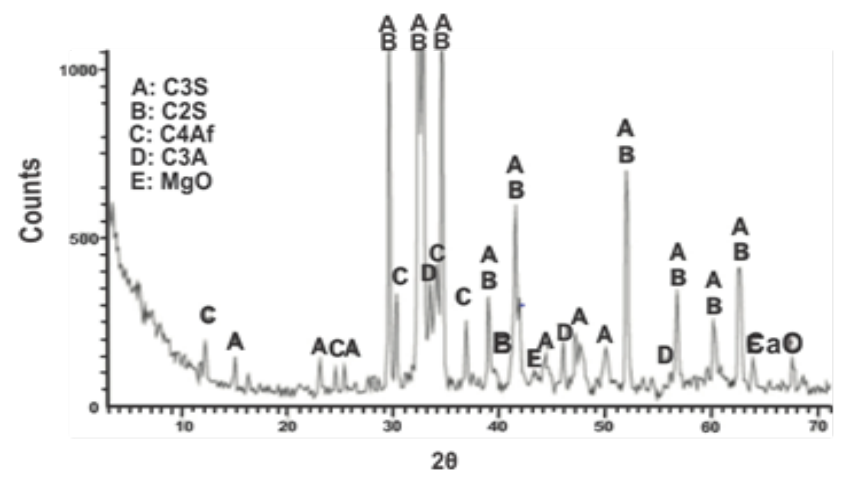

Fig 2. X-ray diffraction of OPC

in OPC are shown in Table $\mathrm{V}$. The mean concentrations of $\mathrm{C}_{3} \mathrm{~A}$ in the LWT, SAT, AWT, ST, and LT are $50 \%, 48 \%$, $50 \%, 50 \%$, and $60 \%$, respectively. These results indicate that $\mathrm{C}_{3} \mathrm{~A}$ content lies within the range recommended by Jordan Standard (50\%-64\%) (JS 30-1:2007) (Falah, 2011) and European Standard (50\%-64\%) (EN 197-1, 2000) specifications for ordinary OPC purposes. Hence, treated PG could be replaced by natural gypsum. The mean percentage proportions of $\mathrm{C}_{4} \mathrm{AF}$ in the LWT, SAT, AWT, ST, and LT are $24 \%, 25 \%, 22 \%, 23 \%$, and $14 \%$, respectively. These results indicate that $\mathrm{C}_{4} \mathrm{AF}$ content agree with the result recommended by Jordan Standard $(26 \%)$ and European Standard (27\%) specifications for OPC purposes (Falah, 2011; EN 197-1, 2000). Therefore, treated PG could be replaced by natural gypsum. The mean percentage proportions of $\mathrm{C}_{3} \mathrm{~S}$ in the LWT, SAT, AWT, ST, and LT are $8 \%, 8 \%, 8 \%, 8 \%$, and $7 \%$, respectively. These results indicated that $\mathrm{C}_{3} \mathrm{~S}$ content lies with the result recommended by Jordan Standard (6\%- 9.5\%) and European Standard (6\% - 9.5\%) specifications for OPC purposes. Thus, treated PG could be replaced by natural gypsum. However, concrete made with OPC having a relatively high $\mathrm{C}_{3} \mathrm{~S}$ content will tend to gain more strength and produce more heat of hydration at earlier ages, usually within the first week of placement (EN 197-1, 2000). The mean percentage proportions of $\mathrm{C}_{2} \mathrm{~S}$ in the LWT, SAT, AWT, ST, and LT are $10 \%, 10 \%, 10 \%, 10 \%$, and $10 \%$, respectively. These results indicated that $\mathrm{C}_{2} \mathrm{~S}$ content conform with the result recommended by Jordan Standard (10\%) and European Standard (10\%) specifications for OPC purposes (Falah, 2011; EN 197-1, 2000). Treated PG could be replaced by natural gypsum. Chandra (1997), specified concrete made with OPC having a relatively high $\mathrm{C}_{2} \mathrm{~S}$ content tends to gain more of its strength at later ages, perhaps up to four weeks after placing. Overall, variation in the chemical constituent of cement affects the hardening/hydration, setting time, corrosion resistance, color of cement (Pandey and Shukla, 1980). The mean ratio of LSF, AR, and SR in OPC is shown in Table V. The mean ratios of LSF in the LWT, SAT, AWT, ST, and LT are 0.94, 0.93, 0.95, 0.94, and 0.98, respectively. These results indicate that LSF content lies within the range recommended by (Noor-ul-Amin, 2010)(0.9-0.98) as specified OPC purposes. Treated PG when replaced by a natural gypsum, can be used in OPC manufacturing process. The mean ratios of AR in the LWT, SAT, AWT, ST, and LT are $1.55,1.55,1.55,1.54$, and 1.43 , respectively. These results indicate that AR content is within the range recommended by Sam et al. (2013) (1.3-2.5) specifications for OPC purposes. However, AR ratio above 2.5 , can develop high early strength and low early strength and low heat of hydration occur if it goes below 1.3 (Sam et al., 2013). It can be concluded that treated PG could be replaced by natural gypsum, and it does not create any problem in cement manufacturing process and OPC strength. The mean ratios of SR in the LWT, SAT, AWT, ST, and LT are 2.56, 2.56, 2.50, 2.55, and 2.56, respectively, and lies within the range recommended by (Noor-ul-Amin, 2010). However, if SR less than 2, burning become very easy but excessive liquid phase and low strength cement is obtained. On the other hand if the SR reaches up to 3, then the high strength OPC is obtained, therefore the burning become very difficult. For SR more than 3, no clinkerization takes place. This indicates that treated PG can be replaced by natural gypsum.

\section{Physical properties of $O P C$}

The blaine surface area, specific gravity, and unit weight test results are presented in Table VI. All samples were milled to a fineness of approximately $3200 \mathrm{~cm}^{2} / \mathrm{g}$ Blaine surface area. The average specific gravity and unit weight of the OPC contains LWR, SAT, AWT, ST, and LT is 2.35 and 2400 $\mathrm{kg} / \mathrm{m}^{3}, 2.40$ and $2480 \mathrm{~kg} / \mathrm{m}^{3}, 2.32$ and $2300 \mathrm{~kg} / \mathrm{m}^{3}, 2.27$ and $2250 \mathrm{~kg} / \mathrm{m}^{3}, 2.50$ and $2500 \mathrm{~kg} / \mathrm{m}^{3}$, respectively. The increase in density of OPC can be attributed to increase specific gravity of additives as compared to that of LT. Unit weight of OPC increased from $2250 \mathrm{~kg} / \mathrm{m} 3 \mathrm{ST}$ to $2500 \mathrm{~kg} / \mathrm{m}^{3} \mathrm{LT}$ was used as fine additives in OPC. However, substantial increases in viscosity and unit weight occur at the concentration at which close packing is reached. The increase of viscosity beyond this limit may be explained by an increase in inter-particle friction due to increased solid-solid contact.

\section{The compressive strengths of the (OPC)}

The compressive strength values of the 2-days and 28-days OPC samples containing the treated PG conform to the corresponding value using natural gypsum and untreated $\mathrm{PG}$ are given in Table VII. The average compressive strength 
results of OPC at 2-days and 28-days in the natural gypsum, PG, LWR, SAT, AWT, ST, and LT is 10 and $42.5 \mathrm{~N} / \mathrm{mm}^{2}, 8.2$ and $30.1 \mathrm{~N} / \mathrm{mm}^{2}, 13.6$ and $35.3 \mathrm{~N} / \mathrm{mm}^{2}, 10.7$ and $31.5 \mathrm{~N} / \mathrm{mm}^{2}$, 12.8 and $35.8 \mathrm{~N} / \mathrm{mm}^{2}, 10.7$ and $35.1 \mathrm{~N} / \mathrm{mm}^{2}$, and 9.5 and 34.5 $\mathrm{N} / \mathrm{mm}^{2}$, respectively. It can be concluded that the

Table VII. Compressing strength tests of OPC containing untreated and treated PG and natural gypsum

\begin{tabular}{rcc}
\hline & 2-days $\left(\mathrm{N} / \mathrm{mm}^{2}\right)$ & 28-days $\left(\mathrm{N} / \mathrm{mm}^{2}\right)$ \\
Natural gypsum & 10 & 42.5 \\
Phoshogypsum & 8.2 & 30.1 \\
LWT-1 & 14.1 & 35.6 \\
LWT-2 & 13.8 & 35.2 \\
LWT-3 & 13.7 & 35.6 \\
LWT-4 & 14.0 & 34.9 \\
LWT-5 & 14.2 & 35.4 \\
LWT-6 & 12.0 & 35.1 \\
LWT-7 & 13.1 & 35.1 \\
Average & 13.6 & 35.3 \\
SAT-1 & 10.2 & 31.5 \\
SAT-2 & 11.1 & 32.4 \\
SAT-3 & 10.5 & 31.4 \\
SAT-4 & 10.8 & 30.8 \\
Average & 10.7 & 31.5 \\
AWT-1 & 12.3 & 38.0 \\
AWT-2 & 13.0 & 38.1 \\
AWT- & 13.2 & 39.5 \\
Average & 12.8 & 38.5 \\
ST-1 & 10.9 & 35.5 \\
ST-2 & 10.7 & 34.9 \\
ST-3 & 10.5 & 34.7 \\
Average & 10.7 & 35.1 \\
LT-1 & 10.0 & 35.1 \\
LT-2 & 9.0 & 34.2 \\
LT-3 & 9.4 & 34.5 \\
LT-4 & 9.8 & 34.8 \\
LT-5 & 9.2 & 34.6 \\
Average & 9.5 & 34.6 \\
\hline & & \\
\hline & & \\
\hline
\end{tabular}

compressive strengths of treated PG at 2-days and 28-days have sufficient strength for OPC applications. These results were confirmed and fulfilled the requirement with the specification of OPC obtained in the Jordan standard (JS 30-1:2007) and according to European standard (EN 197-1, 2000) for the compressive strengths.

\section{Conclusion}

The industrial and laboratory tests performed in this study indicate that $\mathrm{PG}$ can be replaced by gypsum as a set retaider. The various treatment process of the PG in the laboratory and industrial tests indicate the influence of the product, on the parameters illustrating the quality of the OPC. All the parameters are in accordance with the standards Jordan standards and European standards; the PG appears as a substitute of the gypsum at level up to $5 \%$ of constituents.
Nevertheless, times of setting hardening of OPC containing natural gypsum are high compared to those whom obtained with the treated PG; conform to the Jordan standards and European standards. This can be attributed due to the effectiveness of various treatment process that remove the undesirable $\mathrm{MgO}, \mathrm{SO}_{3}$, and $\mathrm{P}_{2} \mathrm{O}_{5}$ in $\mathrm{OPC}$ products. It is observed that the various treatment process of $\mathrm{PG}$ in the laboratory and the tests carried in the industry influence the properties of OPC. The chemical and mineralogical analyses for studied OPC samples after addition of treated PG show that the dominant phases composition are $\mathrm{C}_{3} \mathrm{~S}$ and $\mathrm{C}_{2} \mathrm{~S}$ while the $\mathrm{C}_{3} \mathrm{~A}$ and $\mathrm{C}_{4} \mathrm{AF}$ are less abundant, whereas $\mathrm{CaO}$ and $\mathrm{MgO}$ exhibits as trace phase. These experimental results also showed that the $\mathrm{C}_{3} \mathrm{~S}, \mathrm{C}_{3} \mathrm{~A}$ and $\mathrm{C}_{4} \mathrm{AF}, \mathrm{C}_{2} \mathrm{~S}, \mathrm{LSF}, \mathrm{AR}$, and SR contents achieved the requirement of the Jordan standards and European standards; hence treated PG can be replaced by natural gypsum. Several treatment of PG with LWT, SAT, AWT, ST, LT used in cement mortar mixture has resulted in improvement in the 28-days mechanical properties compared to those of mortars prepared with untreated PG. The percentage improvement in compressive strengths was higher with AWT, whereas the LT compressive strength showed the lowest. Treated PG improves the strength development when used in OPC and hence it can be used in construction industry for preparation of OPC replacing natural gypsum, which is a valuable ingredient of OPC, to achieve economy.

\section{Acknowledgment}

This research was supported by the Al-Hussein Bin Talal University, the Academic Research Deanship (151/2008) dated June 2, 2008. The authors would like to thank the Indo-Jordan Chemical Industry at Eshidiya Mines for phosphogypsum samples, the technical staff and Engineering staff at the Al-Rashadiyeh Cement Factory, South Jordan for chemical analysis and compressive strengths test of OPC mortar produced, the Higher Council for Science and Technology (HSCT), for phosphogypsum chemical analysis. Thanks also go to anonymous journal reviewers.

\section{References}

Al-Hwaiti M, Al-Khashman O, Al-Khatib LA and Fraige FY (2013), Radiological hazard assessment for building materials incorporating phosphogypsum made using Eshidiya mine rock in Jordan. Journal Environmental Earth Science 71(5): 22572266.

Al-Hwaiti M, Ross P and Ranville J (2010), Bioavailability and mobility of trace metals in phosphogypsum from Aqaba and Eshidiya, Jordan, The Chemie der Erde Geochemistry 70: 283-291.

Ali MS, Khan IA and Hossain MI (2008), Chemical Analysis of Ordinary Portland Cement of Bangladesh. Chemical Engineering Research Bulletin 12: 7-10. 
Al-Jabbari S, Faisal F, Ali F and Nasir S (1988), Scientific Research Council, Baghdad, Building Research. (Baghdad), 7: 49-69.

Austin GT (1985), Shreve's Chemical Process Industries, $5^{\text {th }}$ ed. Singapore: McGraw Hill Book Company.

Charles HKL, John PB and Gordon M (2010), Utilization of Incineration Waste Ash Residues in Portland Cement Clinker, Chemical Engineering Transactions 21: 757-762.

Deborah NH and Thomas DE (2009), A life-cycle assessment of Portland cement manufacturing: comparing the traditional process with alternative technologies, Journal of Cleaner Production, 17: 668-675.

Erdogan Y, Demirbas A and Genc H (1994), Partly refined chemical by-product gypsums as cement additives Cement Concrete Research 24(4): 601-604.

European Standard EN 197-1 (2000), Cement - Part 1: Composition, specifications and conformity criteria for common cements prepared by Technical Committee CEN/TC 51.

Falah FBH (2011), Chemical Analysis of Ordinary Portland Cement of Jordan, Ass. Univ. Bull. Environmental Research 14(1): 1-9.

Faleye FJ, Ogunnubi S and Olaofe O (2009), Chemical and Physical Analysis of Selected cement samples in Nigerian market. Bangladesh J Sci. Indus. Res. 44(1) 41-50.

FIPR (Florida Institute of Phosphate Research) (1998), How does Phosphogypsum storage Affect Groundwaters, Final Report FIPR Project No. 94-05-042, Florida Institute of Phosphate Research, pp 110.

Kwon WT, Kim YH, Chu YS, Lee JK, Kim IS, Kim SR (2005), Effect of $\mathrm{P}$ and chloride on clinkering reaction, J. Material Online 1: 1-8.

Lobthenbach B and Winnefeld F (2006), Thermodynamic modeling of the hydration of Portland cement, Cement Concrete Research, 36(2): 209-226.

Natalya GS (2003), Influence of C3S Content of Cement on Concrete Sulfate Durability". A thesis submitted to college of Engineering, University of South Florida.

Neville AM (1996), Concrete Technology, Singapore: Long man Singapore Publishers Ltd. $4^{\text {th }}$ Ed.
Noor-ul-Amin AK (2010), Chemical Analysis and Comparison of Ordinary Portland Cement of Khyber Pakhtoon Khwa, Pakistan Chemical Engineering Research Bulletin 14: 45-49.

Pandey G and Shukla S (1980), A Text Book of Chemical Technology". Vikas Publishing House, New Delhi, India.

Sam RA, Bamford SA, Fletcher JJ, Ofosu FG and Fusein A (2013), Assessment of Quality of the Various Brands of Portland Cement Products Available on the Ghanaian Market, International Journal of Science Technology 2(3): 252-258.

Smadi MM, Haddad RH and Akour AM (1999). Potential use of phosphogypsum in concrete, Cement Concert Research 29(9):1419-1425.

Singh M (2002), Treating waste phosphogypsum for cement and plaster manufacture, Cement Concrete Research. 32(7): 1033-1038.

Tamas KS (2010), Study Aid 1.2-Construction/Building Materials I for Bsc (Civil and Architect Engineering). Ybl Miklos College of Technology, Department of Building Materials and Quality Control, Hungary.

Taylor HFW (1997), Cement Chemistry. Edited by Thomas Telford Edition, London, pp 480.

Van der Merwe EM and Strydom CA (2004), Purification of South African phoshogypsum for use as Portland cement retarder by a combined thermal and sulpheric acid treatment method, South African Journal of Science 100(10): 411-414.

Weiguo S, Gejin G, Rui D, Hu C, Yu T and Mingkai Z (2012), Utilization of solidified phosphogypsum as Portland cement retarder, Material Cycle Waste Management 14(3): 228-233.

Wagner K and Vassilopoulos M (2000), The European Cement Industry-Background Assessment for the IPTS BAT-Competitiveness Project.

Received: 15 March 2015; Revised: 11 October 2015; Accepted: 19 October 2015. 